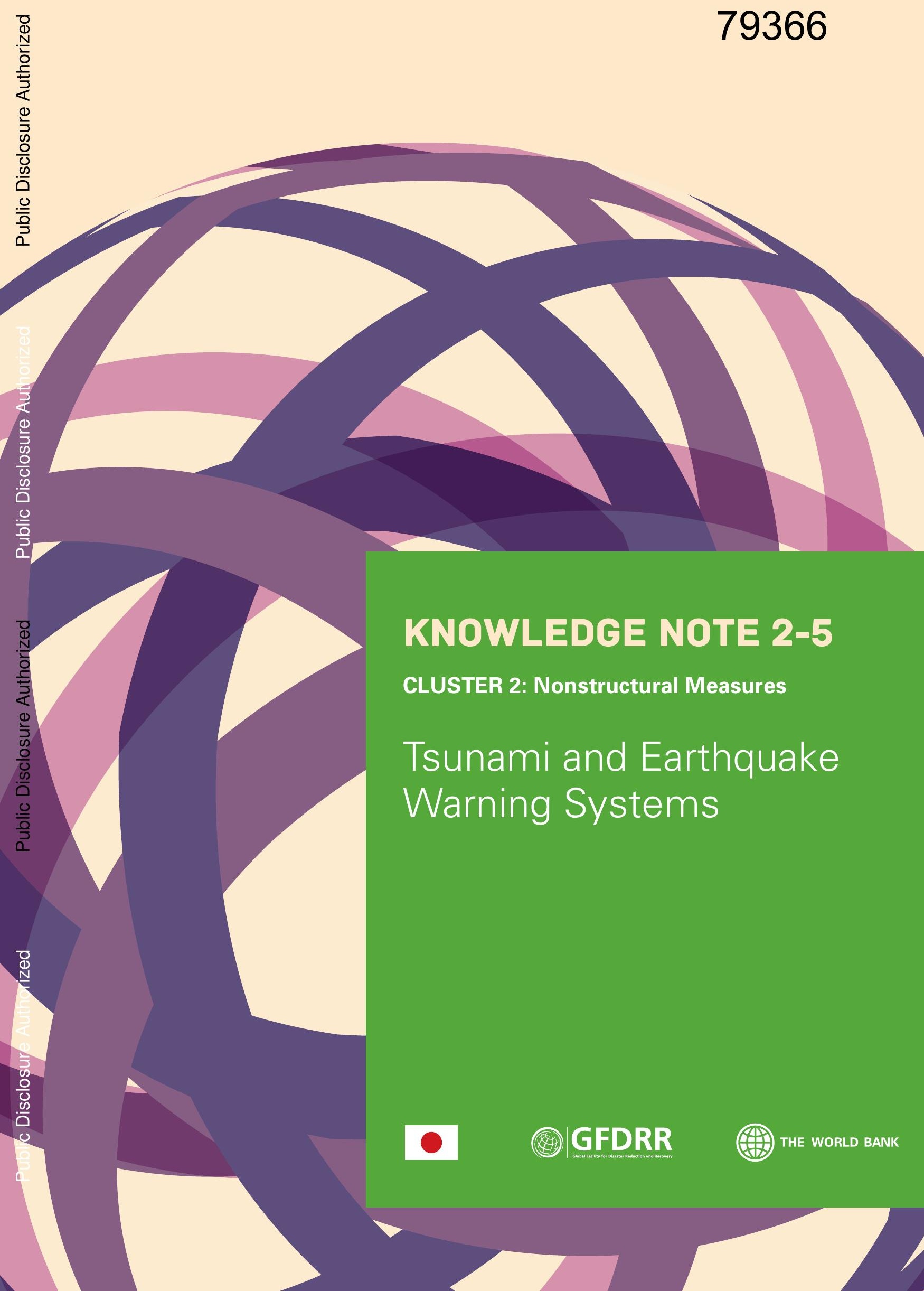


Prepared by Mikio Ishiwatari, World Bank 


\title{
KNOWLEDGE NOTE 2-5
}

\author{
CLUSTER 2: Nonstructural Measures
}

\section{Tsunami and Earthquake Warning Systems}

\begin{abstract}
Warning systems can mitigate the damage caused by tsunamis and other natural events, and prevent the loss of human life and properties. Countermeasures, such as evacuations to higher ground and the stopping of trains, depend on getting the right information and disseminating it in a timely manner. Warning systems must also be aligned with community response. While Japan has developed the most sophisticated tsunami-warning system in the world, the system underestimated tsunami height on March 11 and may have misled the evacuees and increased human losses.
\end{abstract}

\section{FINDINGS}

\section{COMMUNITY-BASED TSUNAMI-WARNING SYSTEMS}

Before March 11, 2011, Japan had already developed sophisticated high-technology tsunami-warning systems that included satellite communications and hundreds of real-time monitoring stations. But on March 11 the community-level response (and community-based warnings) was the key that saved countless human lives. The volunteer fire corps-which are community-based organizations (CBOs) trained in disaster management (see KN 2-1) used various tools such as handheld loud speakers, fire bells, sirens, and fire engine loud speakers to warn communities throughout the affected areas. In Katsurashima, Shiogama City, all community members including 30 disabled people were safely evacuated because the fire corps went door to door to every house, helping community members move to higher ground. In Otsuchi and Natori cities some members of the corps kept ringing fire bells or giving directions on their loud speakers right up until the tsunami hit-some at the expense of their own lives.

\section{TSUNAMI WARNINGS ON A NATIONAL SCALE}

Japan's Meteorological Agency (JMA) monitors seismic activity throughout Japan, around the clock. The agency can quickly calculate the hypocenter and magnitude of an earth- 


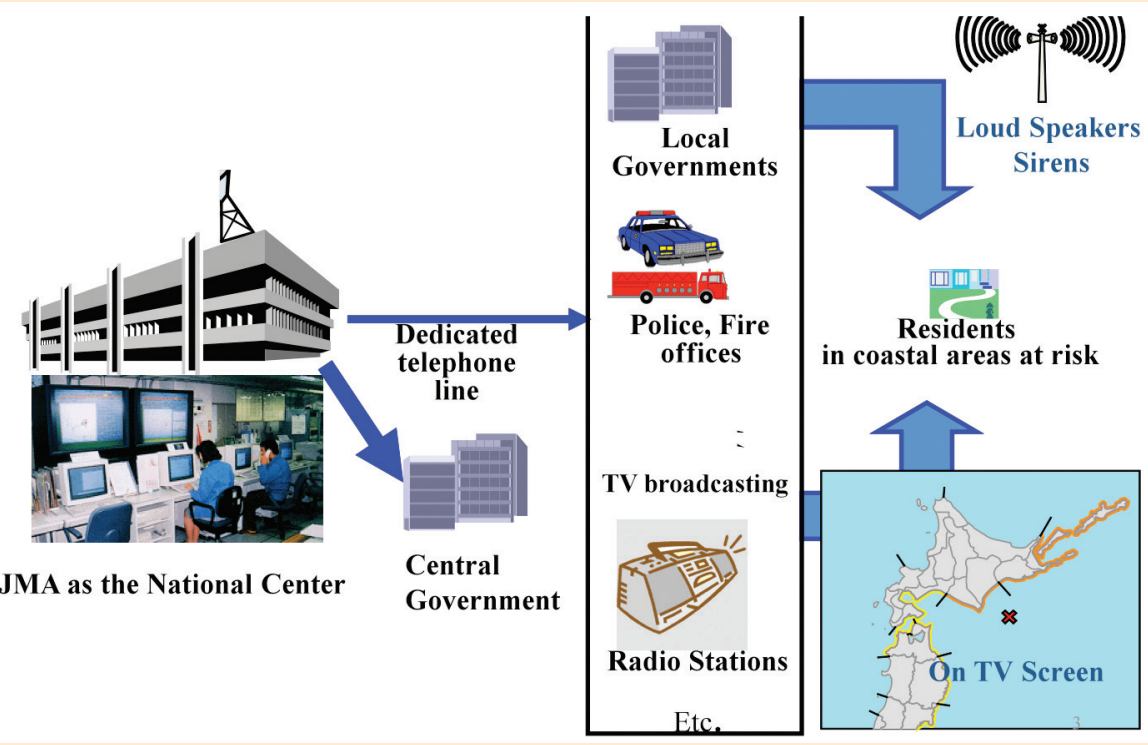

Source: JMA.

quake, and issue a tsunami warning within three minutes after the earthquake. The information is immediately disseminated to the public by disaster management authorities, local governments, and the mass media (figure 1 and box 1). The JMA has recently invested some $¥ 2$ billion in tsunami and earthquake monitoring and warning systems.

On March 11, 2011, the JMA issued the first tsunami warning at 14:49, three minutes after the earthquake. People started evacuating and organizations concerned started preparing for the tsunami.

Critical problems were found in estimating the tsunami's height and getting information out to the public. Underestimation of the tsunami's height likely contributed to the delay in people's evacuation. The agency at first estimated tsunami heights of three to six meters in Iwate, Miyagi, and Fukushima prefectures, well below the actual heights. This was because the agency underestimated the earthquake magnitude as Mj (JMA magnitude)* 7.9, while the actual magnitude was Mw (Momentum Magnitude) 9.0.1 The agency could not calculate the Mw within 15 minutes, as with a normal operation, because of the scalingoff of most broadband seismographs. Cable-type offshore hydraulic gauges, which provide useful forecasting information, were not installed to revise tsunami information. Also, the

* The JMA magnitude has the advantage of being calculated quickly within three minutes, but tends to underestimate the magnitude of earthquakes over M8. The moment magnitude is utilized worldwide but takes around 10 minutes to calculate. 


\section{BOX 1: Tsunami warnings in Japan}

The JMA conducted tsunami computer simulations for various earthquake scenarios, and stored the results (which included tsunami arrival times and heights) in a database. Since the simulation takes some time, the agency cannot promptly issue warnings using real-time simulation following an earthquake. When a large earthquake occurs, the operating system quickly calculates the hypocenter and magnitude, searches the tsunami database for this hypocenter and magnitude, and selects the most appropriate simulation results from the database. Based on the estimated height of the tsunami, the JMA issues a tsunami forecast. Tsunami forecasts fall into two categories: tsunami warnings and tsunami advisories. Warnings are further divided into two classes: tsunami and major tsunami.

The JMA improved the warning systems in 1941 following the establishment of a tsunami-warning unit for the Sanriku coast. The agency expanded it into a nationwide service in 1952; and after the 1960 Chilean earthquake tsunami, the system started covering long-distance tsunamis as well. In the Hokkaido Nansei-Oki earthquake of 1993, the tsunami arrived before any warning was issued. The JMA improved the system, and started issuing estimated tsunami heights in 1999.

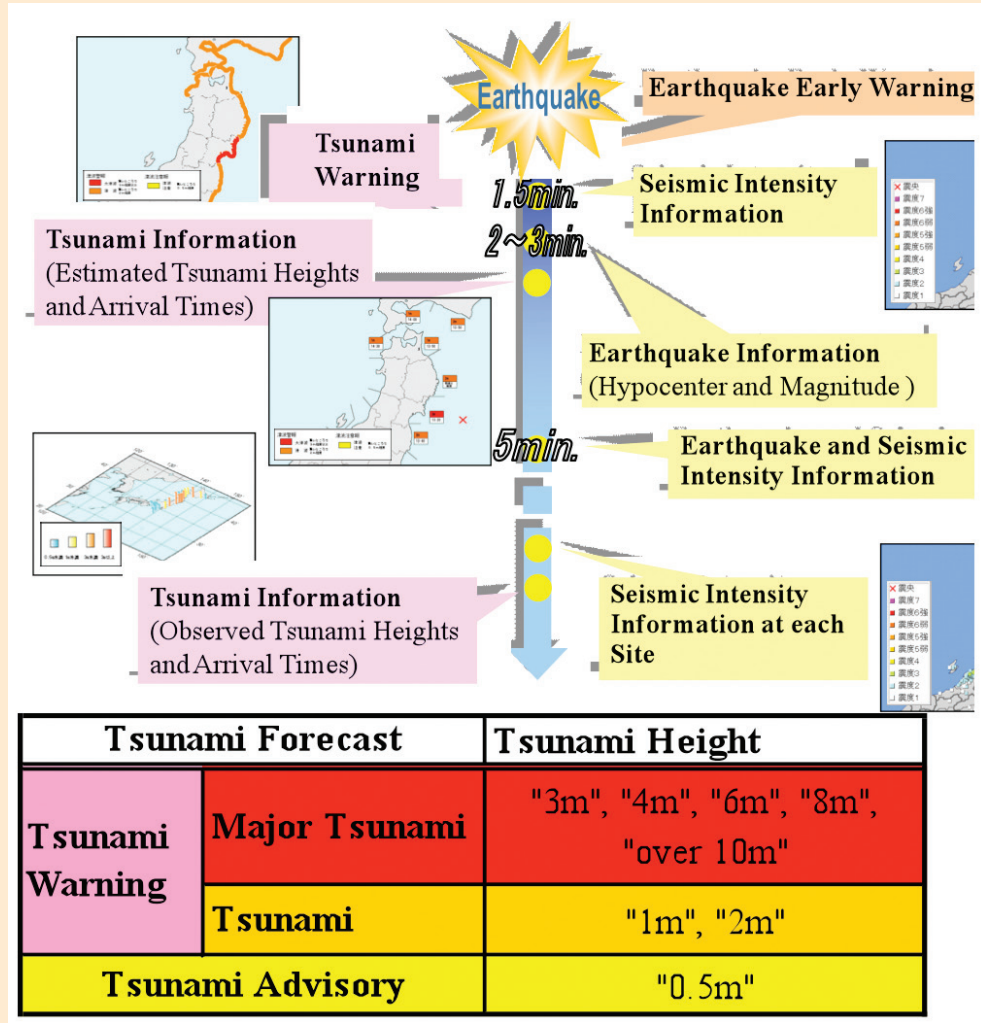




\section{FIGURE 2: Timeline of revised tsunami warnings on March 11, 2011}

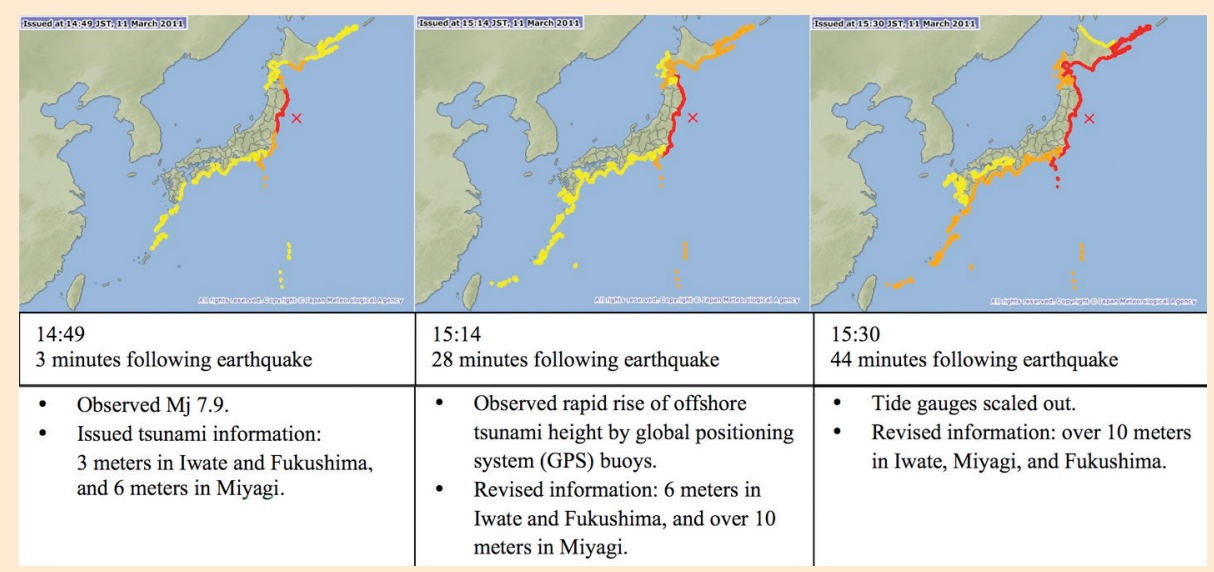

Source: JMA.

Note: $\mathrm{Mj}=$ JMA magnitude

JMA issued information on a 0.2-meter-height tsunami 13 minutes after the earthquake. The agency revised the estimated height to 6 to 10 meters at Iwate, Miyagi, and Fukushima prefectures 30 minutes after the quake, and then to more than 10 meters in 45 minutes (figure 2). The revised information, however, did not reach everyone, since they were evacuating, and power and communication systems had failed due to the earthquake.

According to interview surveys by the Japanese government, almost half of the population received no tsunami information or evacuation orders in the affected areas; and 60-70 percent did not receive the revised information about tsunami heights.

Based on lessons learned from the GEJE, the JMA plans to take the following approach while issuing a warning (figure 3):

- Issue tsunami information that is useful in making decisions about evacuation; the information should be clear and timely, emphasize crucial messages, and encourage evacuation.

- Issue the first warning quickly, within three minutes following an earthquake, and revise it according to observed data.

- Provide tsunami height predictions qualitatively, instead of numerically in the first warning for possible megatsunamis caused by earthquakes greater than M8, considering the uncertainty of tsunami estimates. 
- Raise public awareness of the principle that people should take the initiative on their own to escape from tsunamis when they feel any quakes.

- Improve the accuracy of warnings about frequently occurring tsunamis to better inform people's evacuation decisions by improving confidence.

NHK, Nippon Hoso Kyokai, and Japan Broadcasting Corporation reviewed programs during the GEJE, and found that the tones of the warning announcers on television were rather

\section{FIGURE 3: New methods for tsunami warnings}

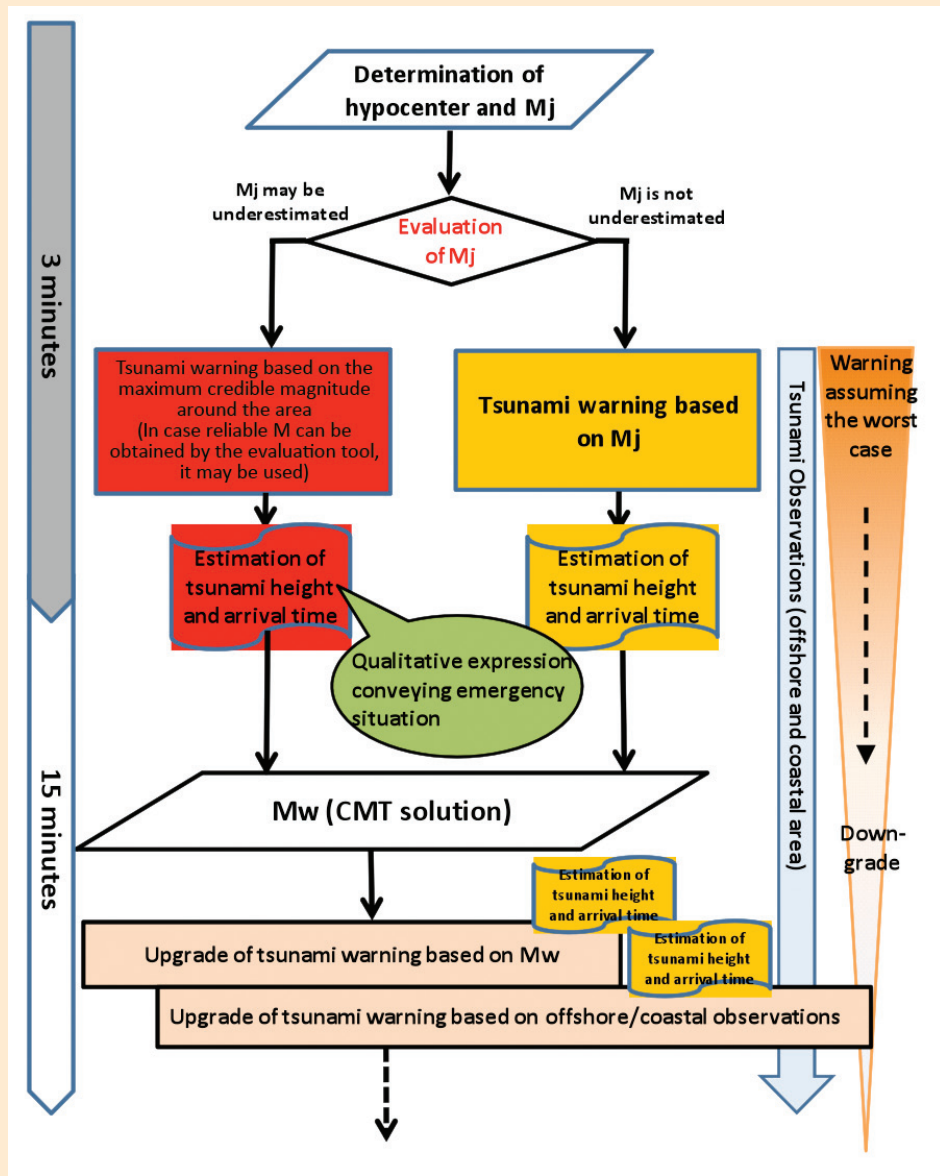

Source: JMA.

Note: $\mathrm{Mj}=$ JMA magnitude; $\mathrm{Mw}=$ moment magnitude 
flat and lacked urgency. The corporation is revising the warning methods issued through television to encourage evacuation by announcements that are persuasive.

\section{THE EARTHQUAKE EARLY WARNING SYSTEM}

The Earthquake Early Warning (EEW) System aims at mitigating earthquake damage by providing a lead time to slow down trains, stop elevators, and give people time to take protective measures (figure 4). The JMA quickly determines the hypocenter and magnitude of an earthquake based on real-time monitoring data. The agency estimates the distribution of strong ground tremors, and issues warnings to government officials and the mass media, such as radio, television, and communication companies before the tremors reach them. For example, gas and train companies use this warning to control their operations. Also, warnings are issued to the public through SMS alerts. The JMA launched this EEW service in 2007.

During the GEJE, the JMA issued the first EEW 8.6 seconds after detecting the first primary wave (P-wave) at the nearest seismic station. There were 15 to 20 seconds of lead time after the warning and before the main shock hit Sendai. At Seisho High School, Kanagawa Prefecture, students used this time to get under their desks or leave -at-risk spots before the main ground tremors arrived. Also, at a primary school where teachers and students had conducted practice evacuation drills, they calmly began evacuating as soon as they got the warning.

\section{FIGURE 4: Earthquake early warning system}

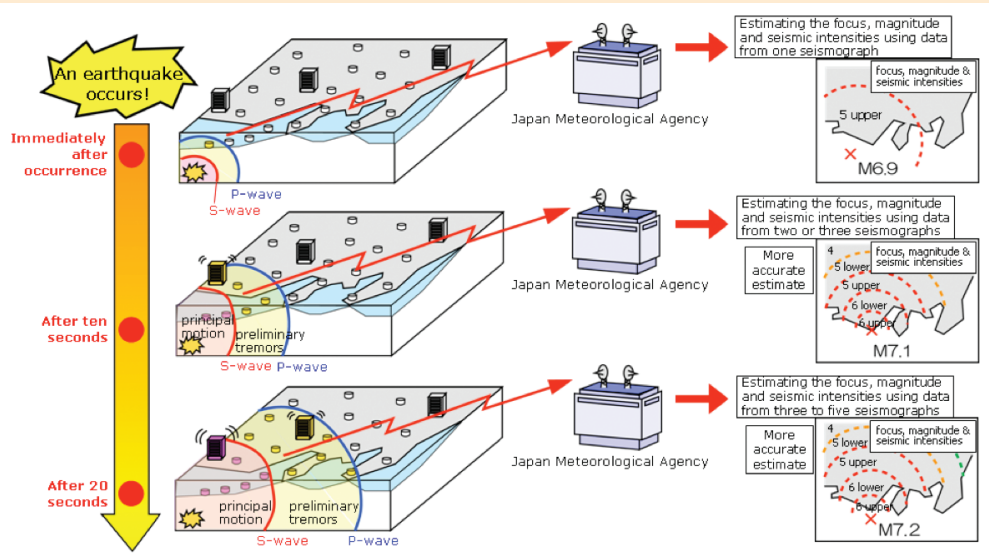

Source: JMA. 
FIGURE 5: Earthquake early detection system

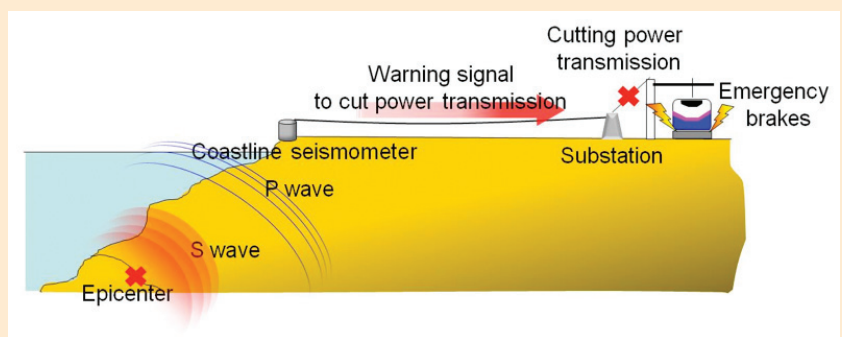

Source: MLIT..

According to a JMA survey, over 80 percent of people believe the EEW information helps them protect themselves. Some 60 percent took action, such as taking shelter under desks, upon receiving the EEW. Although some 40 percent of EEWs have been incorrect and underestimated the actual size of quakes, over 80 percent of respondents want to keep using the system. The JMA is improving the accuracy of the EEW by upgrading prediction models.

\section{BULLET TRAINS' EARTHQUAKE DETECTION SYSTEM}

On March 11, 19 bullet trains (including two traveling close to the maximum speed of 270 kilometers per hour) were running on the Tohoku Sinkansen Line. All trains were able to stop safely soon after the earthquake occurred without incurring any casualties. The system detected the P-wave and stopped the trains by automatically cutting their electricity supplies (figure 5). The railway companies started using the system in 1992, and have improved it since then. During the Chuetsu Earthquake in 2004, a bullet train derailed because it was traveling right above the epicenter, although no causalities were reported. The companies shortened the lead time between detecting a P-wave and issuing the warning, from three seconds to between one and two seconds. The number of earthquake monitoring and detection stations has also increased to 239 across the country.

\section{LESSONS}

The following lessons should help inform the development of warning systems:

- The earthquake warning systems were able to reduce economic damages and loss of life by shutting down bullet trains and providing lead time for people to take protective measures. Japan has developed new technologies to improve these systems.

- Using warning systems to trigger timely community response is the key to disaster management. No matter how advanced technology becomes, the guiding 
principle is that people should take the initiative to escape from a tsunami on their own as soon as they feel any quakes.

- Inaccurate or inappropriate information in a tsunami warning could mislead or delay evacuation and increase the loss of lives. Warning information should be issued on safer side, considering the possible inaccuracy of estimates and the limitations of the forecasting technology.

- Multiple methods of information sharing must be secured. While warnings must be delivered to everyone at risk, only half of the affected residents actually received the information following the GEJE. It was difficult to provide people with revised information during the evacuation because of power and communication system failures.

- Disaster risk communication must be practiced regularly, so that people are able to better understand the information and messages and agencies can better understand the mechanisms that local people use to cope with disasters (KN 5-3).

\section{RECOMMENDATIONS FOR DEVELOPING COUNTRIES}

Warning systems can save people's lives and reduce economic damages from natural disasters such as floods, tsunamis, earthquakes, landslides, and other events. People can take countermeasures, such as escaping to higher ground, protecting themselves from falling debris, and stopping trains before they are overtaken by these events.

Start with low-cost systems. Warning systems can start with simple methods. Low-cost equipment, such as fire bells and sirens, were widely utilized as warning tools during the GEJE. Observers in communities once monitored water levels in rivers and sent information to concerned organizations by phone until a decade ago in Japan. Warning systems can evolve by replacing equipment, such as automatic monitoring equipment and telemeter systems, based on these basic systems.

Link with community-based activities. Actions at the community level are crucial as demonstrated by the volunteer fire corps that issued warnings and saved lives on March 11. Warning systems and other measures organized by communities may be particularly relevant in developing countries where government capacity and resources are limited (box 2).

Develop technology and understand its limitations. Although various technologies, such as flood prediction, tsunami simulations, communication systems, and earthquake monitoring are all needed to develop effective warning systems, their limitations must be taken into account. On March 11, underestimating the tsunami height likely caused people to delay their evacuation and led to greater losses.

Conduct interactive risk communication. Communities, governments, and experts should exchange information and ideas about potential risks (KN 5-3). Communities should be able to understand the information delivered in the warning, while also being aware of the system's limitations. Also, government staff must understand communities' response to disasters to design warning systems. 


\section{BOX 2: Community-based warnings in Sri Lanka}

In Sri Lanka the Disaster Management Center and National Building Research Organization are promoting community-based landslide warning systems. Simple rain gauges, which are bottles for measuring rainfall or bottles equipped with an automatic buzzer (Type OI) were delivered to at-risk communities. When the water level in the bottle reaches the risk level, a warning is issued to community members.

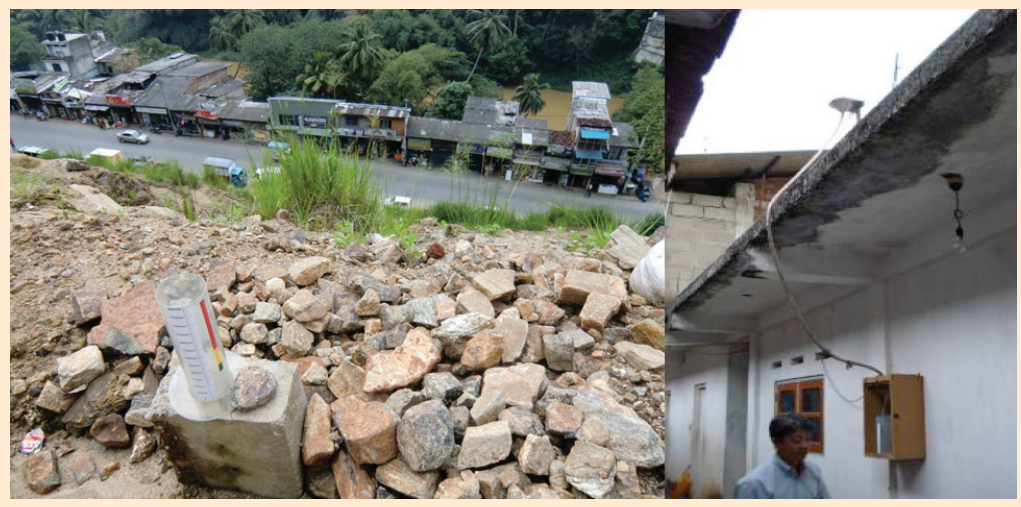

Understand communities' coping mechanisms. Since warning systems are meant to benefit communities on the ground and to inform their actions, the responsible organizations should understand how local people cope with and respond to disasters. Community members decide on their own when, where, and how to escape. The organizations should tailor the contents of warning messages to the users' needs and points of view. Such messages need to be simple, timely, and encourage evacuation.

Establish end-to-end systems to ensure that warnings reach the communities at risk. Multiple communication channels should be established so that information keeps flowing in case of power and communication failures.

Ensure services are available 24/7. Since natural events can happen at any time, the organizations concerned are required to function around the clock-24 hours a day, 7 days a week. Staff rotation should be arranged in the organizations.

\section{KEY REFERENCES}

Goto, M., and N. Aihara. 2012. "Development of Education for Natural Disaster Preparedness and Reduction at School Linking to the Community." In East Japan Earthquake and Tsunami: Evacuation, Communication, Education and Volunteerism, ed. R. Shaw and Y. Takeuchi. Singapore: Research Publishing. 
Ministry of Education, Science, and Culture. 2011. "Interim Report of an Expert Panel on Disaster Education and Disaster Management Based on GEJE." http://www.mext. go.jp/b_menu/shingi/chousa/sports/012/attach/1310995.htm

Ishiwatari, M. "Review of Countermeasures in the East Japan Earthquake and Tsunami." In East Japan Earthquake and Tsunami: Evacuation, Communication, Education and Volunteerism, ed. R. Shaw and Y. Takeuchi. Singapore: Research Publishing.

JMA (Japan Meteorological Agency). 2011. Improvement of Tsunami Warning in light of tsunami disaster by Off the Pacific Coast of Tohoku Earthquake. (in Japanese) http:// www.jma.go.jp/jma/press/1109/12a/torimatome.pdf

- 2002. Survey on Utilization of EWE (in Japanese). http://www.jma.go.jp/jma/ press/1203/22c/23manzokudo_data.pdf

Ohara, M., K. Meguro, and A. Tanaka. 2011. "Comprehensive Study on People's Awareness of Earthquake Early Warning Before and After the 2011 Earthquake Off the Pacific Coast of Tohoku." Seisan Kenkyu (in Japanese) 63 (6): 811-16. 